\title{
Size Effects on the Melting Temperature of Silver Nanoparticles: In-situ TEM Observations
}

\author{
M.A. Asoro*, J. Damiano**, P.J. Ferreira* \\ *Materials Science and Engineering Program, University of Texas at Austin, Austin, TX 78712, \\ USA. \\ ** Protochips, Inc., 617 Hutton St, Suite 111, Raleigh, NC 27606, USA
}

The melting temperature $\left(\mathrm{T}_{\mathrm{m}}\right)$ of a material is crucial for many applications. In bulk systems, the surface-to-volume ratio is small and the curvature of the surface is negligible. Thus, surface effects on $\mathrm{T}_{\mathrm{m}}$ can be disregarded. However, for the case of nanoparticles (NPs), for which the surface-to-volume ratio is large and the surface curvature is high, $\mathrm{T}_{\mathrm{m}}$ is size dependent. This behavior has been explained by thermodynamics theory [1] and shown experimentally by electron diffraction [1], X-ray diffraction [2], differential scanning calorimetry [3] and transmission electron microscopy (TEM ) [4]. However, a systematic in-situ TEM study of size effects on the melting temperature of individual NPs has not yet been done.

In this work, in-situ heating experiments were performed on silver NPs with sizes ranging from $4 \mathrm{~nm}$ to $20 \mathrm{~nm}$ using a JEOL $2010 \mathrm{~F}$ TEM operated at $200 \mathrm{kV}$ and equipped with an Aduro ${ }^{\text {TM }}$ heating stage designed by Protochips. This heating holder is a MEMS design that exhibits an extremely low drift even at high temperatures. The temperature is controlled by a power source supplying current to a thin film that contains the silver NPs and that is heated resistively, allowing very fast heating rates ( $\mathrm{msec}$ ) without sample drift. Starting from room temperature, the sample was heated in-situ in the TEM in increments of $25^{\circ} \mathrm{C}$ until all the NPs melted and vaporized. As the vacuum pressure in the TEM $\left(1.33 \times 10^{-5} \mathrm{~Pa}\right)$ is within the range of the liquid vapor pressure of bulk silver $\left(1.27 \times 10^{-7} \mathrm{~Pa}\right.$ to $6.03 \times 10^{-4} \mathrm{~Pa}$ from $800 \mathrm{~K}$ to $\left.1000 \mathrm{~K}\right)$, we expect the NPs to vaporize and vanish from the support after melting.

A sequence of TEM images showing the melting and vaporization of Ag NPs at various temperatures is shown in Fig. 1. As expected, the smallest NPs disappear at the lowest temperatures. This behavior can also be seen in Fig. 2. The appearance of the first melting for a sphere can be found from the expression [5]

$$
T_{m}=T_{o}\left(1-\frac{2 \sigma_{S L}}{L_{o} r}\right)
$$

where $T_{m}$ is the melting point of a NP with radius $r, T_{o}$ is the bulk melting temperature, $\sigma_{S L}$ is the solid-liquid interfacial energy, and $\mathrm{L}_{\mathrm{o}}$ is the bulk latent heat of fusion. However, as shown in Fig. 2, there are significant differences between what is predicted from equation (1) and the measured $\mathrm{T}_{\mathrm{m}}$, even if we consider the vacuum pressure in the TEM. One possible reason for this might be a change in the solid-liquid interfacial energy due to curvature effects.

\section{References}

[1] C. R. M. Wronski, British Journal of Applied Physics 18 (1967) 1731-1737.

[2] K. F. Peters, Y.-W. Chung, J. B. Cohen, Applied Physics Letters 71 (1997) 2391-2393.

[3] T. Bachels, H.-J. Güntherodt, R. Schäfer, Physical Review Letters 85 (2000) 1250.

[4] Z. L. Wang et al, The Journal of Physical Chemistry B 102 (1998) 6145-6151.

[5] P.R. Couchman, W.A. Jesser, Nature, 269, (1977), 481-483. 


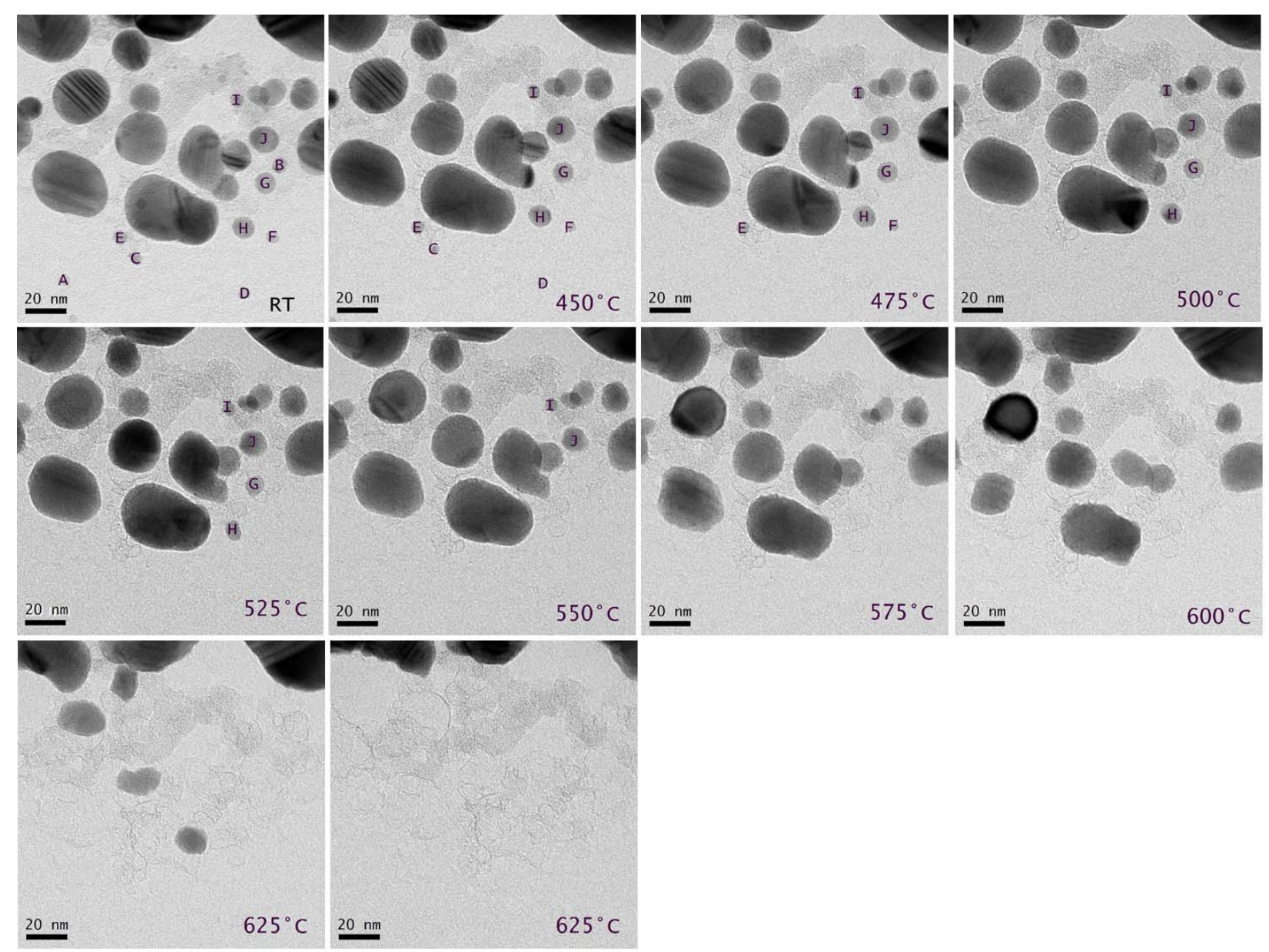

Figure 1: A sequence of TEM images showing melting and vaporization of Ag NPs.

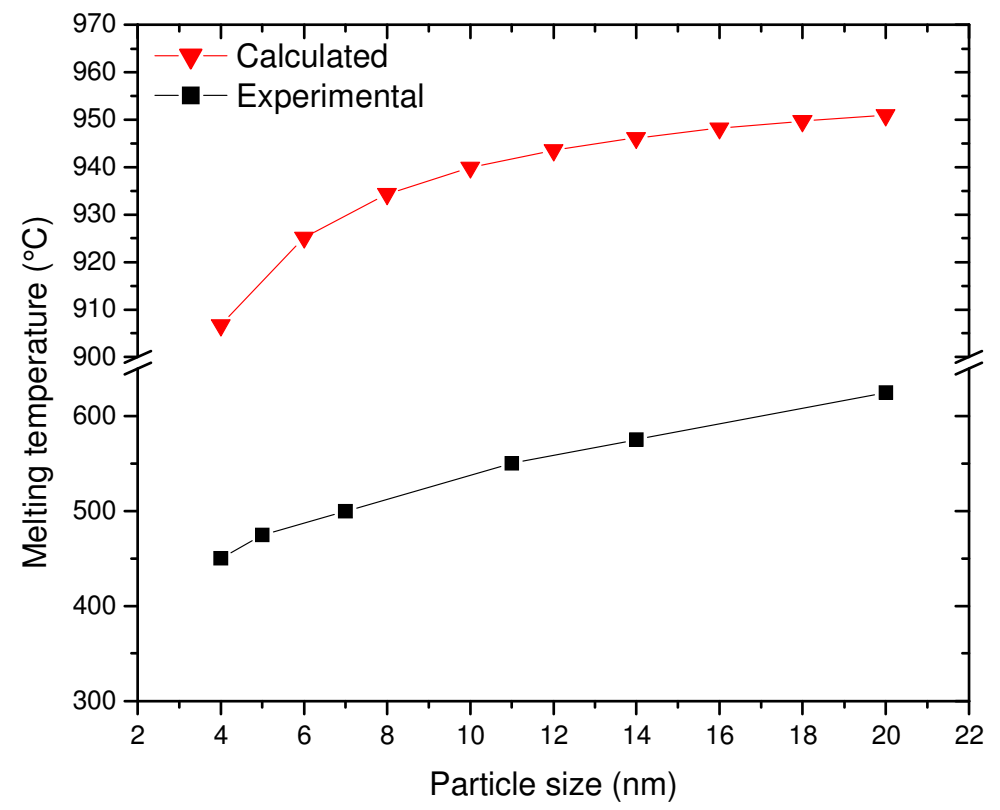

Figure 2: Melting temperature versus size of silver NPs. 